\title{
Bipolar Air Demand in Boilers using Arduino Controller
}

\author{
Dr. C. Esakkiappan, M.E, PhD ${ }^{1}$, Anniesha J.R ${ }^{2}$, Hemalatha $\mathbf{K}^{3}$, Madhumathi $\mathbf{P}^{4}$ \\ Professor \& Head, Dept of Electronics \& Instrumentation, Panimalar Engineering College, Tamil Nadu, India ${ }^{1}$ \\ Dept of Electronics \& Instrumentation, Panimalar Engineering College, Tamil Nadu, India ${ }^{2,3,4}$
}

\begin{abstract}
While it is possible to operate and control a boiler with indicators and recorders alone, efficient and reliable operation through simple control is not optimal these days. Early boilers were smaller and operated with simple, but rising demand for, and cost of, steam production has resulted in larger boilers with increased output. More careful boiler control calls for process instrumentation. Air control is inaccurate and unreliable, particularly when flow rates drop below $25 \%$ of maximum load. Traditional control methods set the fuel-air ratio .This solution cannot correctly compensate for process variables and is slow to respond to varying load conditions. This control element cannot be solely depended on for accurate control. The goal of airflow optimization is to minimize thermal losses and prevention of a starved boiler. Minimizing excess air reduces stack temperature and thermal loss and can only be done utilizing high accuracy airflow measurement devices. The fuel saving potential in a boiler can exceed $20 \%$ in some cases and can lead to substantial savings. Airflow is one of the most important components of boiler control and is critical for safe, reliable, and efficient operation. Incorrect air control can result in toxic gas production, flame outs, fuel-rich conditions and explosion, inefficient operation, erratic cycling, and other issues. Boiler operators need continuous information to adjust the firing rates and distribution of fuel and air to the burners. This can sometimes be difficult to obtain particularly when the air flow is lesser than the demand. It's common to feed excess air to the boiler at all loads to ensure complete combustion of the fuel. However, this practice can reduce efficiency. Too much air means excess fan power and stack loss from unused oxygen. Lesser air means unburnt fuels in stack. A careful balance between fuel and air is necessary for optimum efficiency, which can only be obtained through careful, multivariable measurement of airflow, fuel flow, and analytical analysis of the stack gases.
\end{abstract}

Keywords: Bipolar Air Demand, Boilers, Arduino Controller, Stack Gases.

\section{INTRODUCTION}

The boiler is to be fed with the required quantity of feed. Supplied feed is the crude.This crude contains enormous products, which are further separated depending on the combustion process carried out. Feed provided depends upon the boiler size as it varies accordingly. Fixed amount of air and fuel ratio is to be fed to the boiler for efficient combustion process. The amount of fuel required depends upon the supply air and quantity of air supplied depnds on the amount of fuel. Thus the air fuel ratio determines the efficiency of the system. In this project air supplied is the key factor as the amount of fuel remains constant.Depending upon the air content two sensors are used.If the amount of oxygen is more then it is sensed using an oxygen sensor.On the contrary it cannot detect the defecit amount of oxygen.In order to overcome this issue we use an $\mathrm{CO}$ sensor, as the amount of oxygen provided is inversely proportional to the carbon monoxide produced.

\section{INPUT CONTROLLER OUTPUT}
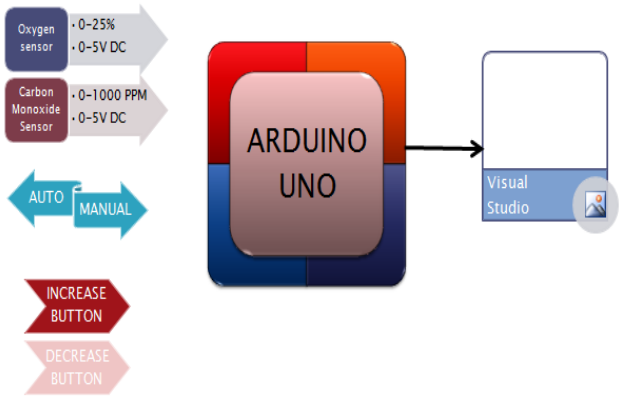

Fig.1 Overview of system 


\section{PARAMETERS MONITORED}

The parameters that are to be monitored are air and fuel ratio, motor speed and excess air. They are monitored using air fuel ratio controller.

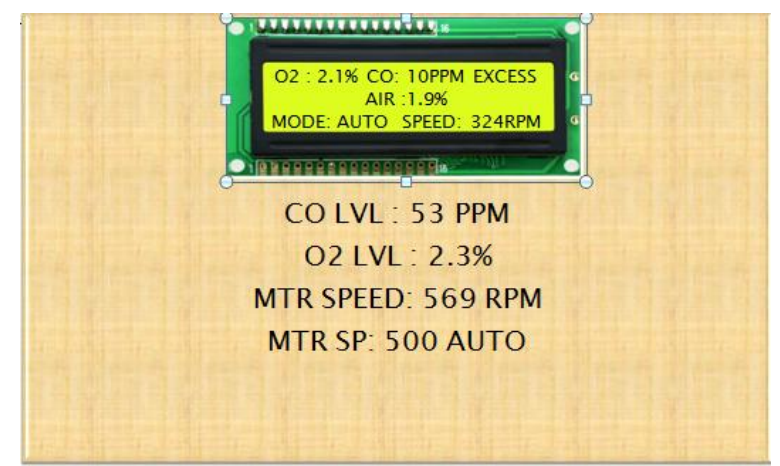

Fig.2 Overview of output panel

\section{EXISTING SYSTEM}

The boiler is supplied with air and fuel through separate feed pipelines. Boiler is filled with crude. Thus a fixed air fuel ratio is provided to the system and combustion process is carried out. But the major drawback is that the density of fuel varies accordingly. As a result the amount of air supplied should also be varied. The air fuel ratio for a boiler is measured by a ratio controller and the controller output controls the damper of the blower. Various disadvantages of existing system are Air deficiency magnitude is not known, Sudden increase in excess air flow, Frequent load changes affect boiler operation,Black smoke of change of load,Waste of fuel and No real time data capturing possible

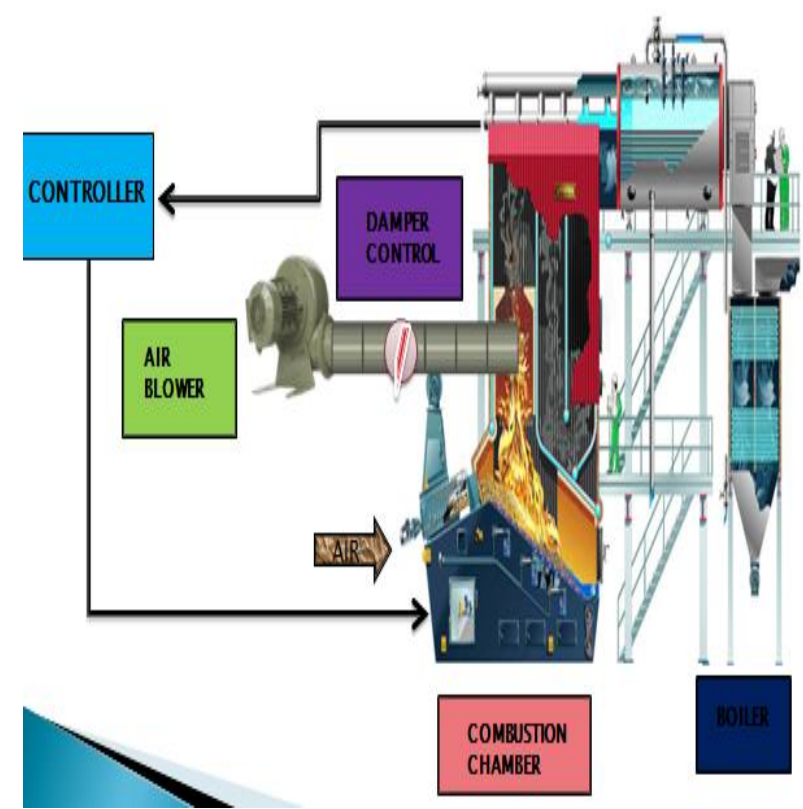

Fig.3 Existing system

\section{PROPOSED SYSTEM}

Our project is aiming for the measurement of air requirement of the combustion process in both positive and negative sides. If the air is more than the required quantity, it can be measured by measuring the percentage of oxygen. But if the air quantity is less than the required quantity, then the oxygen indication will be zero irrespective of the magnitude. In order to overcome this problem, our project measures the deficiency in air by measuring $\mathrm{CO}$ in the flue gas. The signal is very nonlinear in nature. A separate algorithm to be developed to linearize the signal. The final control is shifted from damper to variable speed drive which directly controls the blower speed. Hence the energy supplied to the motor is minimized or saved in accordance with the load changes. 


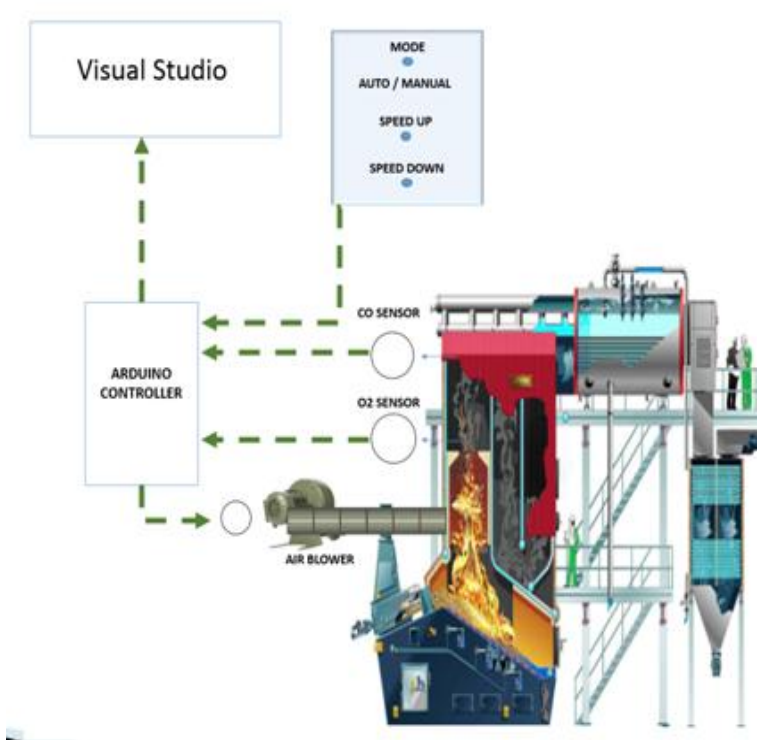

Fig 4.Proposed System

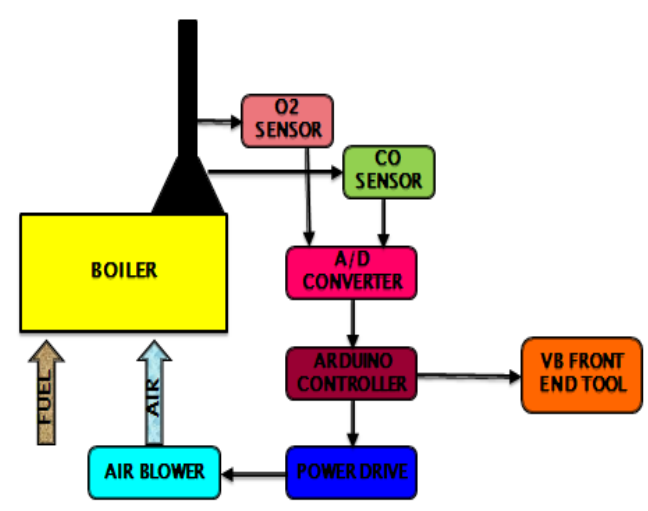

Fig.5 Overview of proposed system

\section{GRAPHICL REPRESENTATION}

When the excess air falls below zero, the controller has no idea to what extend the value has gone and so we incorpate a CO sensor
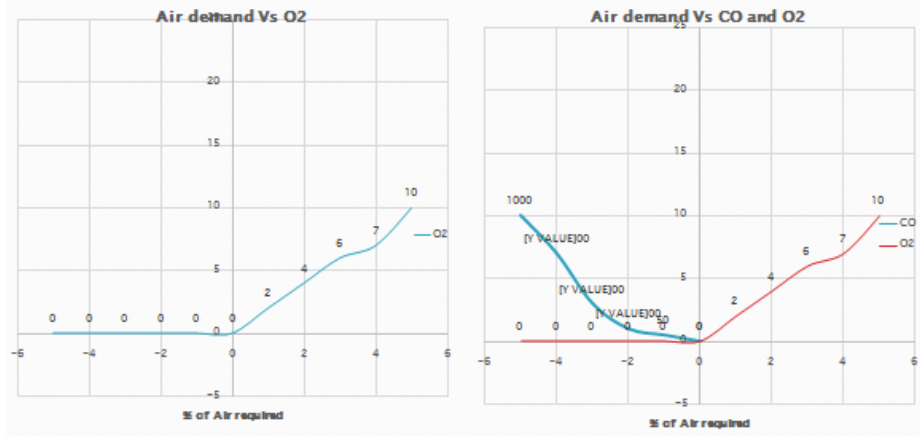

Fig.6 Graphical Representation

VI. VISUAL BASIC

The motor speed,air fuel ratio and excess air are continuously monitored and recorded using the visual baic.Various analysis patterns were incorpated for efficient operation of the system. 
Vol. 6, Issue 6, June 2017

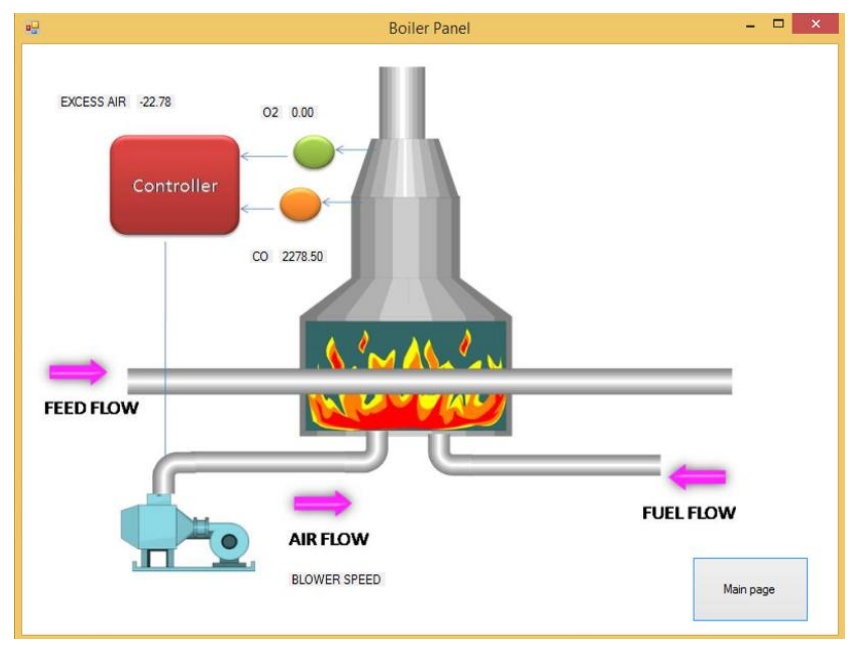

Fig 7.Overview of VB

\section{CONCLUSION}

Amount of excess oxygen is measured using oxygen sensor. Defecit amount of oxygen can be predicted when the amount of carbon monoxide emitted is more. A distinct data acquisition system to be designed using Visual Studio to collect, indicate, store and plot trend. This system will help us to monitor the boiler combustion control in real time basis and analyse the long term.

\section{REFERENCES}

[1] Linear Integrated Circuits, M. Roy Choudhury, New Age Publications, Third edition, 2007.

[2] Chemical Process Control, George Stephanopoulos, Pearson, Pearsons Education Publications, 2006.

[3] Electrical \& Electronics measurements and Instruments, A.K.Sawhney, Dhanpat Rai Publications, Seventh edition, 2005.

[4] Kafarov, "Electrochemical Methods in Soil and Water Analysis", Oxford Univ. Press.

[5] Protection Analysis Eric William Scharpf, The Instrumentation, Systems, and Automation Society (May 1, 2002)Year of Publication: 2012

[6] C Programming for Arduino by Julien Bayle, May 2013

[7] Arduino Cookbook by Michael Margolis, 2013. 